\title{
ADMINISTRAÇÃO PÚBLICA, PRINCÍPIO DA EFICIÊNCIA E ADMINISTRAÇÃO
} GERENCIAL

\section{Manoel Ilson Cordeiro Rocha*}

\section{RESUMO}

O princípio da eficiência administrativa foi adotado pela ciência do direito, tem a sua dimensão jurídica, mas tem extensão e conexão com um amplo debate fora do Direito. Além das ciências jurídicas, ele é de interesse da administração, da sociologia, da economia, da política etc. Pretende-se conceituar e contextualizar a eficiência administrativa na perspectiva geral de eficiência; pretende-se demonstrar a ideia de eficiência como conceito da ciência econômica e da administração e como conceito emergente na administração pública moderna, suas causas e efeitos. São reflexões necessárias para compreender o princípio jurídico.

Palavras-chave: Eficiência; eficiência administrativa; Administração Pública; administração gerencial; Direito Administrativo.

\section{PUBLIC ADMINISTRATION, EFFICIENCY PRINCIPLE AND MANAGERIAL ADMINISTRATION}

\begin{abstract}
The principle of administrative efficiency was adopted by the science of law, has its legal dimension, but has extension and connection with a wide debate outside the law. In addition to the legal sciences, it is of interest to the administration, sociology, economics, politics, etc. It is intended to conceptualize and contextualize the administrative efficiency in the general perspective of efficiency; it is intended to demonstrate the idea of efficiency as a concept of economic science and administration and as an emerging concept in modern public administration, its causes and effects. These are necessary reflections to understand the legal principle.
\end{abstract}

Keywords: Efficiency; administrative efficiency; Public Administration; management administration; Administrative Law.

\section{Introdução.}

A eficiência administrativa, como um princípio para o modo operacional da gestão pública, definido como otimização dos resultados, é resultante de um conjunto de debates de vários campos do conhecimento e repercute no direito administrativo. Um dos conceitos que envolvem o debate sobre eficiência administrativa é o conceito de "administração gerencial". O objetivo principal dessa pesquisa é explorar esse conceito e suas implicações, desde a

\footnotetext{
* Doutorado em Direito (Ciências político-jurídicas) pela Universidade de Lisboa; áreas de atuação: Direito Administrativo; Teoria do Estado; Direito Internacional Público.
} 
origem weberiana da ideia de burocracia até o debate da administração pública no neoliberalismo; outra hipótese é a crise de legitimação que a transição de princípios produz, a ocasionar uma indagação: a que e a quem serve a eficiência administrativa? Por fim, como processo que se instala numa estrutura estatal fundada no direito, como ocorre a garantia da eficiência pelo controle jurisdicional? Essas hipóteses permitem esclarecer a delimitação proposta. Para a análise o método empregado é o dialético e as fontes são bibliográficas.

\section{Eficiência administrativa, burocracia e Direito.}

Primeiramente, a eficiência administrativa pode ser compreendida numa perspectiva atemporal, em sentido amplo, de conduta de gestão otimizada, válida em qualquer circunstância que vislumbra o melhoramento de uma gestão, pública ou privada. Mas pode-se compreender também como um modo operativo típico, aplicável a um contexto histórico de reforma dos processos de administração. Neste último sentido eficiência foi associado tanto à revolução burocrática weberiana, quanto à "administração gerencial" ou a "nova gestão pública" pós-burocrática contemporânea.

Eficiência administrativa não se opõe, necessariamente, à burocracia. Os processos de formação burocrática do Estado Moderno não contradiziam a perspectiva de eficiência de sua administração. A burocracia necessária do Estado não pode ser rotulada indiscriminadamente como a causa da ineficiência do Estado, isto é um raciocínio demasiadamente simplista. Não se pode negar a importância do desenvolvimento da burocracia - na passagem do Estado Liberal clássico para o Estado Social e dos estudos de burocracia por Max Weber -, com fins inclusive à eficiência administrativa, que já não se encontram em voga, mas que não podem ser absolutamente negligenciados quando se contextualiza a concepção de eficiência administrativa.

Em consequência da passagem do Estado neutral de raiz liberal para o Estado de bemestar subjacente à concepção do Estado Social de Direito, a administração pública sofre uma profunda revolução: ao aumento de serviços públicos necessários à concretização das novas tarefas estaduais, adiciona-se a especialidade e tecnicidade do elemento humano, além da exigência de maior eficiência operacional" (OTERO, 1992, p. 360). 
O modo operativo burocrático superou o clientelismo, o nepotismo e o patrimonialismo histórico nas administrações, conferindo impessoalidade, especialização e organização funcional. São inegavelmente medidas de melhora de gestão.

Em termos gerais, a burocracia consiste numa forma de organização da administração pública (e das organizações empresariais) que se baseia na racionalidade e adequação dos meios aos fins a atingir, procurando-se a maior eficiência com a maior segurança e os menores custos.

Max Weber, considerado o pai da teoria da burocracia, concebeu a burocracia como a organização que é, por excelência, eficiente e segura. Só posteriormente surgiu o conceito de burocracia como disfunção do sistema burocrático (eficiente), no sentido de uma excessiva ligação dos funcionários às normas e rotinas, com claro prejuízo da eficiência. O termo burocracia passou, pois, a designar os defeitos do sistema burocrático. É nesse sentido que a lei portuguesa impõe a 'desburocratização' (SOUSA, 2012; p. 59).

No Estado burocrático weberiano a eficiência correspondeu (i) à constituição de quadros funcionais hierarquizados com base num sistema de carreiras especializado; (ii) a quadros funcionais selecionados segundo critérios de mérito e qualificação técnica; (iii) a uma estrutura de gestão e de seleção impessoal; (iv) à distribuição clara das esferas de competência; (v) à realização transparente dos processos de seleção da burocracia; (vi) ao cargo como única ocupação do burocrata; (vii) à separação objetiva entre a administração e a propriedade privada do burocrata; (viii) à disciplina rigorosa de controle do cargo (ARAGÃO, 1997).

No campo do direito, a burocracia weberiana contribuiu para a racionalização necessária à preservação de fundamentos do Estado de Direito, como as garantias de devido processo legal, de segurança jurídica, de isonomia e de impessoalidade. Implicou na procedimentalização que compatibilizou princípios diversos de uma sociedade complexa. Especialmente para a perspectiva democrática, o procedimento pode contribuir para a sua legitimação, quando garante regras de organização do poder sob condições impessoais e a partir de referências de igualdade e de liberdade.

A administração pública Burocrática surgiu na época do Estado liberal, mais precisamente na segunda metade do século XIX, tendo por finalidade combater o nepotismo e a corrupção inerentes à administração patrimonialista. Possui os seguintes princípios orientadores, dentre outros: a) profissionalização; b) ideia de carreira; c) hierarquia funcional; d) impessoalidade; e) formalismo. Tais princípios podem ser sintetizados no chamado poder racional legal, de que fala Max Weber (SANTOS, 2003, p. 251).

Entretanto, o êxito que a burocratização obteve em sua matriz se converteu em sua própria antítese, de estrutura ineficiente por natureza, de processos que causam a ineficiência 
por existirem. A burocracia, que veio para conferir eficiência à administração, estranhamente, se converteu em instrumento de ineficiência. As razões para isso estão no excesso de burocracia ou na burocratização inadequada. A burocracia weberiana se comprometeu ante a eficiência ao inverter os valores: o predomínio do meio sobre o fim.

A solução, em termos práticos, ocorre pela definição da quantidade de burocracia necessária, que identifique a fronteira entre a burocracia para a eficiência e a burocracia com ineficiência. O que ocorreu nos modelos burocráticos weberianos foi uma desproporção de burocracia e uma estagnação nas reflexões de adequação de sistemas às suas necessidades de operação.

Mas a mudança que veio contemporaneamente implicou numa alteração paradigmática. A mudança que ocorre, de fato, na atualidade, é um refluxo da burocratização para um nível suportável. Enfim, não há reflexão razoável que compreenda o Estado contemporâneo sem burocracia, ainda que eco da crítica à burocracia como um empecilho à eficiência administrativa no Estado Social ofusque a compreensão adequada do papel histórico que ela possui no Estado de Direito.

A burocracia é, pois, um instrumento de correção, eficiência e segurança da acção. Deste modo, o 'princípio da desburocratização' previsto na Constituição e reafirmado na lei ordinária (antes de mais no art. $10^{\circ}$ do CPA) como uma ordem dirigida ao legislador e à administração tem de ser entendido apenas no sentido de um dever de se eliminar e evitar toda a burocracia excessiva e injustificada, mas nunca a burocracia necessária e imprescindível (SOUSA, 2012; p. 60).

Na perspectiva histórica atual, de modo operativo de administração gerencial (Nova Gestão pública - NGP), eficiência administrativa corresponde a uma resposta às crises do Estado, da administração e do fisco, que ocorrem desde a década de 70, a indicar soluções privatistas, em geral, denominadas neoliberais. Entretanto, são novos modelos de gestão burocrática que ultrapassam essa perspectiva.

La duda sobre el porvenir del Estado providencia no debe interpretarse sólo, por lo tanto, desde el punto de vista de la regulación de los equilibrios económicos que lo rigen. Sus causas no son sólo la amplitud del Estado o el peso de los gastos sociales. Tiene una raiz más profunda: lo que está em cuestión son las relaciones de la sociedad em el Estado. Si hay uma crisis, es em este sentido. Pero, por qué la crisis aparece precisamente ahora? Por qué hablar de un quebranto tan radical si su origen parece ser un simple desajuste en las finanzas públicas? Em mi opinión, hay tres explicaciones posibles: $1^{\text {a }}$ Incluso teniendo un programa de 'liberación de la necesidad' ilimitado, el Estado providencia há producido ya una importante redución de las desigualdades. La cuestión de los objetivos (la igualdad, el bienestar colectivo) se plantea ahora de manera más precisa. En este contexto, se formula la duda sobre la igualdad como objetivo social. (...). $2^{\mathrm{a}}$ En un contexto de crisis económica, la sociedad está menos 
exteriorizada, el crescimiento no ejerce su función de lubricante social. La cuestión de la unidad de la sociedad y el problema de 'vivir juntos' se plantean de manera más explícita. (...). $3^{\text {a }}$ El Estado providencia siempre ha sido atacado y criticado por ciertos intereses. Pero su existencia y su crecimiento estuvieron presididos por un compromiso social. Lo que ahora ha cambiado es que esos ataques están encontrando eco en algunos sectores sociales que, en pasado, tenían interés em el se produce um cruce de críticas de la derecha y de insatisfación de la izquierda (ROSANVALLON, , 1995, p. 46).

O modelo de administração gerencial impõe à burocracia estatal um comportamento direcionado aos fins do Estado. O procedimento é uma ferramenta necessária e útil, desde que destinada à realização ótima das finalidades públicas. O que ocorre pelos seguintes fundamentos: (i) avaliação de desempenho da burocracia; (ii) aplicação de técnicas de controle orçamentário do setor público; (iii) descentralização administrativa; (iv) delegação de autoridade; (v) administração por objetivos (ARAGÃO, 1997; p. 120).

\section{Eficiência, neoliberalismo e administração gerencial.}

Os discursos neoliberais são recorrentes em exigir eficiência administrativa do Estado. Mas o que razoavelmente se verifica é que, atualmente, não há equivalência necessária entre Estado mínimo e Estado eficiente. Novas formas de esquerda no Ocidente democrático também tem se apoderado do conceito de eficiência para a sua reflexão sobre o Estado. Há a "coincidência" histórica e há o protagonismo neoliberal na defesa da eficiência administrativa, mas esta já não é a atualidade da administração gerencial, com uma esquerda que também adotou os discursos de nova gestão, sem, entretanto, adotar o discurso de Estado mínimo. De forma que administração gerencial e eficiência do Estado são bandeiras comuns a direitas e esquerdas contemporâneas (sem negar que há diferenças entre elas). Em situações opostas, o debate é o seguinte:

É comum formulações que se contrapõem em torno da rotulação da eficiência administrativa como princípio neoliberal, o que nos parece mais um jogo onde todos estão certos na mesma medida em que não estão. Eficiência é um conceito que pode ser apropriado por discursos ideologicamente distintos, e isso ocorre em tempos de administração gerencial. Extraímos dois exemplos neste sentido: "Reclama-se do Estado, cada vez com maior impaciência, para que otimize o seu agir e conduta em termos adequados a realização dos fins prezados pela comunidade. Questiona-se a omissão no agir, a aptidão do agir e a qualidade do agir estatal. Essas exigências não são dirigidas a um Estado liberal, mas a um Estado democrático e social, executor e fomentador da prestação de serviços coletivos essenciais (MODESTO, 2000, p. 106). O que se produziu na literatura de Direito Administrativo após a promulgação da Emenda Constitucional no ${ }^{\circ}$ 19/98 representa irrefutável prova de rendição de muitos de nossos doutrinadores ao sedutor discurso neoliberal-eficientista. Sem se darem conta 
do perverso giro epistemológico a que estavam submetidos, ou entregando-se à cômoda e reconfortante posição de conivência e cumplicidade, muitos dos administrativistas deste país - com seus manuais de grande penetração acadêmica acabaram por docilmente servir ao projeto eficientista, difundindo no âmbito do ensino jurídico a marca epistêmica neoliberal (MARCELINO JUNIOR, 2007, p. 189). O programa originário da NGP compreende que caem em duas dimensões essencialmente diferentes: umas visam a redução da esfera da própria administração pública, outras têm por objetivo 'gestionalizar' a Adminsitração pública. Mas a filosofia de fundo é a mesma: se a gestão privada é mais eficiente do que a pública, esta deve ser reduzida ao mínimo; naquilo que não possa ou não deva ser privatizado, a gestão pública deve procurar emular a gestão privada (MOREIRA, 2013, p. 175).

Quando se busca uma referência histórica para o neoliberalismo é lugar comum, principalmente na América Latina, identificar o "Consenso de Washington" e suas dez teses de controle, abertura e redução do Estado, mas na literatura sobre o modelo de Estado Gerencial não há, necessariamente, a coincidência com as ideias de um Estado mínimo para a administração pública. Por exemplo, segundo Drucker, o ponto de partida para uma "performance eficiente" da administração pública é: (i) ter objetivos claros; (ii) realizá-los cada um por vez, definindo prioridades; (iii) ter mão-de-obra reduzida e qualificada; (iv) não fazer experiências em larga escala; (v) fazer as coisas que são possíveis para si e no tempo certo, tendo adquirido experiência e feedback para isto; (vi) ter capacidade de abandonar o insucesso. Por fim, Drucker afirma que a gestão deve se preocupar com o seu desempenho, o autor mira a eficiência da administração (DRUCKER, 1980). Também a administração gerencial pauta a aproximação com os modos de gestão privada ou a transferência, para a gestão privada, de um conjunto de atividades até então reservadas ou executadas pelo setor público. Entretanto, mais porque o setor privado corresponde melhor à percepção de otimização dos resultados e não, necessariamente, porque se pretende ofertar à iniciativa privada oportunidades de investimento em atividades lucrativas retidas pelo Estado.

O principal objetivo da NGP, tomada em sentido estrito, é a transposição de mecanismos e métodos da gestão privada em geral, e da gestão empresarial em especial, para a esfera da gestão administrativa pública, mediante a importação de categorias e conceitos económicos para a área da administração pública (gestão, mercado, empresa, valor acrescentado, eficiência, 'orientação para os custos', concorrência, consumidores/clientes, 'orientação para o cliente', custo-benefício, etc.). A ideia fundamental é substituir a administração pública pela gestão pública, e aproximar esta da gestão privada (MOREIRA, 2013, p. 176).

Se a administração gerencial tem uma gênese neoliberal, hoje sua dimensão é superior, especialmente por primar por eficiência administrativa, pertence a agendas diversas, já que o princípio da eficiência não se prende à orientação privatista e corresponde também a propósitos republicanos. 
É inquestionável a ligação originária da NGP à revolução neoliberal. Todavia, como se referiu acima, importa distinguir duas vertentes na NGP: (i) as propostas ligadas à redução do perímetro da administração e à privatização de serviços públicos ('menos Estado, mais mercado'); (ii) as propostas de organização e funcionamento da gestão administrativa tendentes a conferir-lhe maior capacidade de resposta e maior eficiência. Se a primeira vertente compartilha obviamente dos objetivos neoliberais, já a segunda, sobre novas formas de gestão, é compatível com outros entendimentos, menos 'desintervencionistas', do Estado e da administração (MOREIRA, 2013, p. 177).

A administração gerencial implica num conjunto amplo de reformas para a administração pública. Com certeza a eficiência administrativa é um dos seus pilares, senão o mais importante princípio. Quando ela não é reclamada diretamente (avaliação de desempenho, ênfase nos resultados, controle orçamentário, avaliação prévia de condutas), é invocada por outros caminhos associados, como a privatização - em todas as suas variantes: alienação do patrimônio público; adoção de formas privadas de gestão; delegação de atividades (segundo um pressuposto de que a iniciativa privada seja mais eficiente); a autonomia gerencial (para fazer escolhas menos rígidas e mais eficientes); controle a posteriori (para conferir a eficiência).

A crise do Estado que fomentou reformas neoliberais e a adoção de administrações gerenciais é a crise do Estado Social. Mas isso não quer dizer que a administração gerencial é antagônica à administração de um Estado Social, este é uma proposta aberta e não há um modelo de Estado Social pronto e acabado. Entretanto, para explicar as crises que alimentaram os movimentos de reforma é inevitável identifica-las com o Estado Social.

\section{Crise e reforma do Estado Social e a administração gerencial.}

O que ocorre é que as promessas da modernidade de emancipação do indivíduo (pela liberdade e pela igualdade) atingiram um padrão substancial no Estado Social (SANTOS, 1995), mas as leis de mercado sob uma economia globalizada e fragilizadora das fronteiras tradicionais do Estado pôs em xeque a sua efetividade (ROSANVALLON, 1995, p. 25).

A política gradativa de proteção de direitos fundamentais esbarrou na limitação natural dos recursos públicos e na limitação decorrente de uma concorrência entre economias e mercados capitalistas globalizados, com um respectivo Estado preso ao controle fiscal, ao endividamento público e à redução da tributação. Por outro lado, o endividamento público e a precarização dos serviços públicos são atribuídos tanto a um crescimento da demanda por 
esses serviços, quanto a um crescimento desmensurado da máquina pública e dos seus custos, como também a hipóteses de ineficiência de gestão.

Lo decisivo de esta crisis es, consecuentemente, el dato de la limitación de los recursos a disposición del Estado, que - a estos efectos - es primariamente Estado administrativo, y, por tanto, el imperativo de la priorización el gasto y la gestión más útil de los recursos económicos, como también de los materiales y personales, puestos a su disposición. La Administración, a la que em el período de Estado liberal de Derecho se le exigía sólo la correcta aplicación del Derecho y, con el desarrollo de las políticas sociales, pasó a requerírsele, cada vez más, eficacia y eficacia distinta en cada uno de sus ramos y sectores de actividad - lo que explica la aparente pérdida por el Derecho del monopolio de ordenación y explicación de la actividad administrativa , le es demandada ahora, además, eficiencia en la eficaz realización del interés general conforme a su determinación por el Derecho (ALFONSO, 2003, p. 145).

A partir dos anos setenta do século XX os Estados entraram em ciclos de inflação, desemprego crescente e déficit de produtividade, com a consequente elevação dos custos da proteção do emprego e com a erosão do poder aquisitivo popular pelos processos de inflação. Vejamos como exemplo que pode ser generalizado a descrição de Agustín Gordillo para a Argentina:

\begin{abstract}
A fines de la década del 80 y comienzos del 90 en el siglo XX se produce entre nosotros una fuerte iniciativa en materia de privatización y desregulación, creándose marcos regulatorios para algunas de las atividades privatizadas y entes de control sobre ellas. La constitución de 1994 enfatiza el rol de tales entes en su art. 42, pero es mucho lo que falta para el control de los servicios privatizados y la protección del usuario y del consumidor. Todo esto debe ver-se en el contexto de la crisis de endeudamiento y déficit a la estructural en las postrimerías del siglo y consecuente imposibilidad de atender de igual manera a los objetivos sociales preexistentes (GORDILLO, 2003, p. II-11).
\end{abstract}

Há uma associação direta destas crises com a elevação dos preços do petróleo naquela década, mas também, mais um ciclo de revolução industrial, que gera concorrência internacional e desemprego.

Em resposta à crise, ocorreram as reformas de gestão da administração pública, que se estenderam pelo ocidente democrático desde a década de oitenta do século passado e ainda é atual.

Il disegno della pubblica amministrazione che Il legislatore sembra aver traciato nelle riforme, Il cui maggiore sviluppo si è avuto negli anni novanta, ma che proseguono ancora oggi in um processo di 'riforma permanente', vede riconosciuto al principio di efficienza um ruolo innegabilmente centrale (PAGLIARIN, 2007, p. 2).

Nesse mesmo caminho, foi a privatização de empresas públicas, com a transferência para a iniciativa privada de atividades até então desempenhadas pelo poder público, 
comumente ocorreram com atividades de potencial lucrativo. Também ocorreu uma fuga, na administração pública, do regime publicista para o direito privado. Técnicas de administração privada foram adaptadas e incorporadas à administração pública.

$\mathrm{O}$ argumento que justifica a evidência da eficiência é a racionalização com fins a reduzir o custo social da estrutura pública, agigantada em decorrência da sua crescente burocracia e da crescente demanda por institucionalização das relações sociais.

la idea del prgreso ilimitado, sostenida por el avance continuado de la ciencia y la tecnología y su explotación por el sistema productivo, y, por tanto, del perfeccionamiento de la función redistribuidora del Estado, gracias al suministro de recursos públicos proporcionado por el crecimiento econômico sostenido, ha quebrado por razón del agotamiento del esquema propio de tal crecimiento provocado, en lo fundamental, por la combinación de las contigencias a las que está expuesto el propio sistema económico con la evidencia de los límites impuestos por los equilibrios básicos de la naturaleza y las fuentes mismas de la energía, así como, en un mundo definitivamente de dimensiones planetarias, la imposibilidad de la generalización del modelo econômico-social de consumo tendencialmente ilimitado establecido en el llamado mundo desarrollado. De ahí la crisis del Estado fiscal, que há dado lugar en algunos países y también en el nuestro, en los años setenta y ochenta, a la formulación y ejecución de políticas dirigidas bien a reducir la extensión o la intensidad de la responsabilidad social del Estado, bien a replantear los términos de ésta. Particular mención rerece en este sentido el control del crecimiento del gasto público, de un lado y con carácter coyuntural, el esfuerzo de reducción del déficit público exigido a los países miembros de la Comunidad Europea por el programa de convergência, y, de outro lado y con carácter estructural, la decisión - a nivel comunitário - de 'independizar' del sistema político, transfiriéndola al sistema europeo de bancos centrales, la política monetária (ALFONSO, 2003, p. 144). Nos regimes que se seguiram ao colapso do socialismo no Leste Europeu, a destruição das solidariedades sociais e a crescente desigualdade foram naturalizadas como contrapartida inevitável da democracia liberal. Nos países industrializados, passou-se a denegrir as instituições públicas enquanto se louvava e idealizava os mercados globais. A eliminação progressiva dos direitos sociais, o apelo à responsabilidade individual e à austeridade fiscal dos governos eram justificados como condição para uma economia saudável. Nesse contexto, a cidadania redefiniu-se como escolha privada do consumidor em vez de participação cívica, causando a erosão do conceito e da prática da vida pública (DUPAS, 2003, p. 40).

A eficiência, na administração gerencial, significa a adoção de medidas de flexibilização para a redução de procedimentos produtivos e estatais e de custos sociais privados e públicos (desburocratização). Uma flexibilização também caracterizada pela competitividade e pela produtividade. Implica uma perseguição extremada aos resultados, com a legitimação da administração (pública e privada) à medida que se atingem os resultados pretendidos, em detrimento dos meios e dos procedimentos. Esses devem ser os mais reduzidos possíveis para um fim alcançado ao menor custo possível (economicidade e produtividade). 
O Estado Social é caracterizado por uma grande participação estatal na vida dos cidadãos com a promoção de benefícios sociais reconhecidos como direitos fundamentais e emancipadores da condição humana. Do outro lado, o discurso neoliberal se fundou na lógica primária de funcionamento do sistema capitalista de produção, de liberação da atividade econômica às leis de mercado e de Estado mínimo. É um discurso que combate um Estado interventivo sob o argumento da sua inviabilidade e sob a alegação de que os custos dos seus procedimentos e das suas demandas sociais crescem sempre acima do crescimento econômico e ameaça corroer os cofres públicos e gerar uma situação insustentável. Mas este jogo ideológico não é tão simples, a adoção da administração privada em setores públicos não significa sempre uma melhora de resultados, também há custos operacionais típicos da atividade pública, assim como responsabilidades típicas desta atividade que a administração privada não pode substituir, ignorar ou suprimir. Isto significa, muitas vezes, a anulação das vantagens na mudança de modelo operativo.

A eficiência significa a adoção de medidas de flexibilização para a redução de procedimentos produtivos e estatais e de custos sociais privados e públicos. Implica uma perseguição extremada aos resultados, com a legitimação da administração (pública e privada) à medida que se atingem os resultados pretendidos, em detrimento dos meios e dos procedimentos. Esses devem ser os mais reduzidos possíveis para um fim alcançado ao menor custo possível.

\footnotetext{
Para Freitag, o modo de reprodução que marca a transição para a pós-modernidade constitui o triunfo de uma lógica organizacional e sistêmica centrada sobre eficiência e eficácia aplicadas ao controle do meio circundante; ele se baseia na realização de operações que possuem um fundamento puramente utilitário ou estratégico imediatista, sem nenhuma visão de longo prazo ou das implicações societárias (DUPAS, 2003, p. 41).
}

Esse ambiente é explorado ao limite numa sociedade global, com a eliminação cada vez maior das barreiras estatais, entre elas as de ordem pública que caracterizam uma gestão pública burocrática e social. A administração do Estado é pressionada a gestões mais dinâmicas, flexíveis e, principalmente, eficientes e de baixo custo financeiro.

\section{Reformas legais gerenciais e a legitimação pela eficiência.}

O eixo dessas crises do Estado foi e é, principalmente, a insustentabilidade financeira, porque a realização do Estado Social implicou custo e burocracia. Entretanto, essas 
crises ocorrem também como crises de legitimidade do sistema regulador, que definem o modo operacional do Estado Social, especialmente porque é um Estado altamente regulado.

Da um lato si è notato come di fronte alla transizione dallo Stato liberale classico allo Stato sociale, com Il conseguente moltiplicarsi degli interessi, anche a volte antitetici, che reclamano e ottengono tutela in sede legislativa, la legge abdichi sempre più spesso al compito di ordinazione, limitandosi ad evidenziare la loro rilevanza. Di modo che 'la definizione dell'interesse destinato a trovare, nel caso concreto, tutela nella forza del potere pubblico non appare più um dato, posto in via generale dal legislativo che ne affida la realizzazione al potere esecutivo, ma Il risultato di um processo decisionale che si svolge nella (e com l') attività amministrativa'. Del resto, si è osservato che nella stessa disciplina del procedimento amministrativo convivono più anime: all' esigenza di provvedere in tempi papidi - propria dei principi di efficacia e economicità - si contrappongono, infatti, le esigenze, de matrice prettamente pubblicistica, di rendere evidenti le ragioni dell' azione, di consentire agli interessati Il proprio aporto collagorativo e, più in generale, di configurare la scelta amministrativa come Il momento riassuntivo di una istruttoria completa e articolata, in grado di permettere una scelta ponderata e fondata su um ricco quadro di riferimento (PAGLIARIN, , 2007, p. 5).

O modelo moderno de regulação, de império da lei, não consegue mais acompanhar o ritmo de mudanças sociais e não resiste à força reguladora do Poder Executivo, como um órgão pragmático e mais eficiente na resposta reguladora. O regulamento administrativo ganha preponderância, assim como a participação do Poder Executivo na elaboração das leis (especialmente nos Estados presidencialistas), enquanto que o Poder Legislativo assume cada vez mais uma função fiscalizadora, dentro do próprio processo legislativo. Para justificar essa mudança, é comum apontar a morosidade do debate nas casas legislativas e também o seu conhecimento insuficiente de questões técnicas, contrapondo a tecnicidade e objetividade dos órgãos da administração, numa sociedade tecnicista, em constante mutação, exigente de muita informação e com pouco tempo disponível para as realizações públicas.

Nos primórdios da modernidade, o Estado racional buscou um atenuante à problemática da falta de segurança, característica do subjetivismo pragmático; na tentativa de recuperação da legitimidade perdida, encontrou um novo mito: a Lei. Ao lado da eficiência, o direito legal passou a ser, então, o meio simbólico de aferição da legitimidade. Entretanto, na contemporaneidade, este instrumental não mais satisfaz, ampliando-se o déficit de legitimidade, haja vista que a eficiência aparenta estar novamente só. A Lei, que inicialmente surge para colaborar com a exigência eficientista do Estado racional, o qual deve buscar a satisfação da vontade dos cidadãos, agora é julgada culpada, justamente pelo seu fracasso em conferir legitimidade a um ente que, em seu apogeu, é considerado ineficiente. (...) A pósmodernidade vem oferecer uma resposta até certo ponto pré-moderna ao problema: a eficiência auto-satisfativa, cujo valor é intrínseco; retorna-se ao problema inicial da legitimação moderna, com a novidade de que o novo mito, a eficiência como valor autônomo, adquire uma real potencialidade legitimadora, ainda que abdicando da moral e do Direito (GABARDO, 2003, p. 80). 
É nesse sentido que a eficiência do Estado assume uma função legitimadora. A crise da legitimidade da legalidade estrita também está por trás da ênfase contemporânea no princípio da eficiência. É quando o sistema reage em busca de eficiência, mas com o desafio de preservar a sua eficácia e a sua efetividade.

No âmbito do sistema político, a eficácia e a efetividade estão relacionadas com a oferta real de direitos sociais e serviços públicos de qualidade. Porém, são perspectivas diretamente relacionadas com a capacidade financeira do Estado. O Estado já impõe pesadas cargas tributárias e já realizou cortes de despesas significativos com fins a equilibrar o orçamento. A eficiência é vislumbrada como a alternativa que otimiza os recursos. Eficácia e efetividade, nessas condições, dependem de eficiência.

É neste cenário que o Estado Social é acusado de ser oneroso, insustentável e ineficiente. É neste cenário que a administração gerencial o reforma.

Em Portugal, por exemplo, ocorreu seguidas reformas de cunho administrativo gerencial, desde a criação de órgãos públicos e a transformação dos modelos de gestão para este fim, revisões constitucionais e infraconstitucionais, privatizações etc. Por exemplo, a revisão constitucional de 1989 é importante nesse sentido, pois buscou a descentralização e a autonomia local da administração pública, com fins à desburocratização, assim como suprimiu a irreversibilidade das nacionalizações, abrindo caminho para as privatizações. $\mathrm{O}$ discurso da eficiência também está presente na legislação administrativa portuguesa nas últimas décadas. São exemplos a lei 8/90, de bases da contabilidade pública, o decreto lei 191/99, do regime da tesouraria do Estado, a lei 42/98, de finanças locais, a lei 27/96, do regime jurídico da tutela administrativa e, recentemente, com maior impacto, a lei 12-A/2008, que regula os regimes de carreira dos trabalhadores da administração pública com fins a uma gestão mais privatista e dinâmica e, por fim, em mudança ainda mais recente, a adoção do princípio da eficiência no artigo $5^{\circ}$ do Código de Procedimentos Administrativos.

Depuis 1986, on a au Portugal un Secrétariat pour la Modernisation Administrative (SMA) qui a pour but d'appuyer le Gouvernement dans les tâches de la modernization de l'Administration Publique.

Depuis lors, son action continue vise à contribuer à la réforme graduelle de l'Administration Publique. Vers la fin de l'année 1998, un texte a été publié qui établit les nouvelles missions et compétences de ce Secrétariat (DL n ${ }^{\circ}$ 395/98, du 17 décembre) défini en tant que 'service public doté de l'autonomie administrative', et ayant pour mission 'l'étude, la conception, la promotion et le soutien à l'exécution de mesures et de projets dans le domaine de la modernisation administrative'.

Selon les termes de ce texte, le SMA prétend notamment 'rapprocher l'Administration Publice et les citoyens, garantissant une plus grande citoyenneté et une meilleure 
gouvernementabilité; promouvoir la création d'une nouvelle culture de gestion faisant appel à l'optimisation des services, dans une perspective créative et innovatrice de la rationalisation des moyens et de la qualité des résultats; contribuer à la definition administrative de la gestion et de la qualité du servisse public, ainsi que l'accueil el la transparence de l'Administration Publique" (OLIVEIRA, 1998, p. 606)

A administração pública portuguesa atual repercute o fenômeno geral de administração gerencial. A acompanhar a sua regulação neste sentido, há grande descentralização, desconcentração, adoção pública de modos privados de gestão e transferência de atividades à gestão privada.

No Brasil a eficiência tornou-se princípio constitucional da administração pública, mas são exemplos também a lei de responsabilidade fiscal, a imposição de tetos de vencimentos, as reformas da previdência e a lei de improbidade administrativa. Entretanto, o Brasil foi precoce em suas reformas gerenciais, já o Decreto n. 200/67 realizou uma importante reforma nesse sentido.

Os militares promoveram, com a ativa participação de civis, a reforma administrativa
de 1967 , consubstanciada no decreto-lei 200 . Esta era uma reforma pioneira, que
prenunciava as reformas gerenciais que ocorreriam em alguns países do mundo
desenvolvido a partir dos anos 80 , e no Brasil a partir de 1995 . Reconhecendo que as
formas burocráticas rígidas constituíam um obstáculo ao desenvolvimento quase tão
grande quanto as distorções patrimonialistas e populistas, a reforma procurou
substituir a administração pública burocrática por uma "administração para o
desenvolvimento": distinguiu com clareza a administração direta da administração
indireta, garantiu-se às autarquias e fundações deste segundo setor, e também às
empresas estatais, uma autonomia de gestão muito maior do que possuíam
anteriormente, fortaleceu e flexibilizou o sistema do mérito, tornou menos burocrático
o sistema de compras do Estado (BRESSER-PEREIRA, 2001, p. 14).

Vale destacar a afirmação de Bresser-Pereira - intelectual e personagem na reforma administrativa brasileira de 1995 - de que essa reforma não se destinou a um propósito neoliberal, mas a uma administração eficiente e republicana. (BRESSER-PEREIRA, 2001, p. 25).

\section{A administração gerencial e o controle jurisdicional da eficiência administrativa.}

Há uma questão prévia a se responder diante deste contexto de administração gerencial: o novo modo operativo da administração pública, fundado especialmente no princípio da eficiência, resulta numa administração flexível, menos regulada e mais dinâmica conforme os fins a que se destina. Ela afeta diretamente o direito administrativo tradicional de Estados como Portugal e o Brasil. Pois eles pautados no princípio da legalidade e impõem às 
suas administrações uma gestão rígida e condicionada aos meios de conduta legalizados. Como um vetor de flexibilização administrativa - a eficiência - se converte num recurso de controle externo? Os controles não impõem rigidez? Admitir o controle jurisdicional da eficiência administrativa não significa retirar parte da essência da administração gerencial, que é a sua flexibilidade pela autonomia administrativa para resultados mais eficientes? Efetivamente nada disto ocorre. A administração gerencial pressupõe que os instrumentos de controle continuem, porém, se renovem. O controle, externo ou interno, é garantia de eficiência. Quando interno funciona como auto avaliação, quanto externo funciona como limitador de desvios. Por outro lado, o controle, especialmente o externo, é um pilar do Estado de Direito, é condição sine qua non, qualquer forma de regulação administrativa não o pode excluir, pode, no máximo, atenuar.

Por fim, a administração gerencial não extingue a conduta administrativa, apenas muda o seu modo de operação. Mesmo as novas técnicas de gestão possuem limites, ainda que ocorra a flexibilização do princípio da legalidade. Há, como visto acima, condicionantes da administração pública, de interesse público, que não podem ser suprimidas. São responsabilidades legais que não podem ser suprimidas no Estado de Direito.

O controle jurisdicional da eficiência administrativa se situa numa margem estreita, porque a administração gerencial é mais flexível, de controle mais difícil. Ironicamente, essa margem seria mais larga se ocorresse numa administração de tipo burocrática, mais rígida. Mas ele atende ao que é mais importante na conduta administrativa: a averiguação dos fins da administração, especialmente por um controle posterior. Historicamente os controles sobre a administração ocorrem sobre os seus meios. Nos fins sempre se avistou a discricionariedade e a liberdade política. O controle jurisdicional da eficiência administrativa não se dá no campo da discricionariedade e da liberdade política, mas, ao mirar os fins da administração, apresenta contornos mais precisos para a sua discricionariedade, descortina uma discricionariedade falsa e vincula a juízos plausíveis de eficiência (dentro da legalidade).

\section{Conclusões.}

Eficiência administrativa é um conceito atemporal, primeiramente foi identificado pelo padrão burocrático weberiano, depois se tornou um princípio de administração gerencial. 
Podemos concluir que a eficiência administrativa é uma decorrência da ordem republicana e do Estado de Direito, como trato adequado da coisa pública, e está no gene do Estado burocrático moderno, como necessária à garantia dos princípios da revolução liberal. A ideia de eficiência jurídico-administrativa coincide com a perspectiva histórica e conjuntural neoliberal, mas vai além, como um princípio básico de boa administração. Mesmo diante da perspectiva contextual de administração gerencial, a eficiência administrativa é, antes de tudo, um princípio atemporal para a administração pública no Estado de Direito.

Como administração gerencial ou Nova Gestão Pública, corresponde à adoção de soluções privadas de gestão, consideradas melhores no alcance dos fins pretendidos. Também como administração gerencial é associada ao neoliberalismo, em sua perspectiva de privatização.

Mas o conceito de eficiência ultrapassa a perspectiva neoliberal e corresponde a um princípio de avaliação de desempenho, que não é, necessariamente, uma opção pelo privatismo, mas sim, pelas experiências bem sucedidas no universo privado.

A eficiência administrativa também se tornou uma referência para a reforma do Estado Social, que o preserve, especialmente pela redução de procedimentos e pela sua otimização na concretização dos fins do Estado Social. A percepção atual é de que a conjugação entre a eficiência administrativa e o Estado Social (nestes Estados) é necessária à legitimação da administração gerencial.

A eficiência administrativa é um desafio para o Estado contemporâneo, tanto pela sua imanência que se deduz para a administração pública num Estado de princípio republicano, quanto pela emergência contemporânea do princípio da eficiência como modo operativo dos sistemas.

\section{Referências bibliográficas.}

ALFONSO, Luciano Parejo. Derecho Administrativo. Barcelona: Editorial Ariel, 2003.

ANDRADE, Alberto Guimarães. Entre a abstração e a realidade: desafios e potencialidades para o estímulo à atuação profissional eficiente. In: BATISTA JUNIOR, Onofre Alves; CASTRO, Sérgio Pessoa de Paula. Tendências e perspectivas do Direito Administrativo: uma visão da escola mineira. Belo Horizonte: Editora fórum, 2012. 
ARAGÃO, Cecília Vescovi de. Burocracia, eficiência e modelos de gestão pública: um ensaio. In: Revista do Serviço Público. Ano 48, no 3, 1997; p. 120. Disponível em: http://repositorio.enap.gov.br/handle/1/1334 consulta em 06.08.2018.

BATISTA JUNIOR, Onofre Alves. Princípio Constitucional da Eficiência Administrativa. Belo Horizonte: Mandamentos, 2004.

BRESSER-PEREIRA, Luiz Carlos. Do Estado patrimonial ao gerencial. In: PINHEIRO, Wilheim e SACHS (orgs.). Brasil: um século de transformações. São Paulo: Cia das Letras, 2001.

COSTA, Paulo Nogueira da. O Tribunal de Contas e a boa governança. Contributo para uma reforma do controlo financeiro externo em Portugal. Coimbra: Coimbra Editora, 2014. DRUCKER, Peter. The Deadly Sins in Public Administration. In: Public Administration Review. Ed. Blackwell Publishing. Vol. 40, nº 2, 1980, pp. 103-106.

DUPAS, Gilberto. Tensões contemporâneas entre o público e o privado. São Paulo: Paz e Terra, 2003.

ESTORNINHO, Maria João. A fuga para o Direito Privado. Contributo para o estudo da actividade de direito privado da administração pública. Coimbra: Ed. Almedina; 2009.

GABARDO, Emerson. Eficiência e legitimidade do Estado: uma análise das estruturas simbólicas do direito político. Barueri, SP: Manole, 2003.

Princípio constitucional da eficiência administrativa. São Paulo: Dialética, 2002.

GORDILlO, Agustín. Tratado de Derecho Administrativo. Parte general. Tomo $1.7^{\mathrm{a}} \mathrm{ed}$. Belo Horizonte: Del Rey/Fundación de Derecho Administrativo, 2003.

MARCELINO JUNIOR, Julio César. O princípio constitucional da eficiência administrativa e a ética da libertação: uma leitura a partir da obra de Enrique Dussel. In: Revista Eletrônica Direito e Política. Itajaí-PR, vol. 2, n. 2, 2007.

MENDIETA, Manoel Villoria. In: GABARDO, Emerson. Princípio constitucional da eficiência administrativa. São Paulo: Dialética, 2002. 
MODESTO, Paulo. Notas para um debate sobre o princípio da eficiência. In: Revista do Serviço Público. Ano 51, n. 2, abr.-jun. 2000.

MOREIRA, Vital. "Nova Gestão pública" e direito administrativo. In: Revista de Legislação e de Jurisprudência. Coimbra: Coimbra Editora. Ano 142, no 3978, jan.-fev. 2013.

.. Novas formas de organização da administração do Estado. In: As

Conferências do Marquês - A administração pública e os desafios de um futuro próximo ( $2^{\circ}$ ciclo). Lisboa: INA, 2000.

OLIVEIRA, António Cándido Macedo de. Portugal - Choniques de vie administrative. In: Annuaire Européen d'Administration Publique. Université de droit, d'économie et des sciences d'aix-Marseille. Volume XXI, 1998.

OTERO, Paulo. Conceito e fundamento da hierarquia administrativa. Coimbra: Coimbra Editora, 1992.

PAGLIARIN, Carola. Autonomia, efficienza, responsabilità: lineamenti costituzionali. Torino: G. Giappichelli Editore, 2007.

PUCEIRO, Zuleta. O processo de globalização e a reforma do Estado. In: FARIA, José Eduardo (org.). Direito e Globalização Econômica: implicações e perspectivas. São Paulo: Malheiros, 1996.

ROSANVALLON, Pierre. La crisis del Estado providencia. Madrid: Editorial Civitas, 1995.

SANTOS, Alvacir Correa dos. Princípio da Eficiência da administração. São Paulo: LTr, 2003.

SANTOS, Boaventura de Sousa. Pela mão de Alice: o Social e o Político na Pósmodernidade. São Paulo: Ed.Cortez, 1995.

SOUSA, António Francisco de. Por uma burocracia de Estado de Direito. Revista da Faculdade de Direito da Universidade do Porto. Ano IX - 2012; pp. 59-78. 
VILLA, Jesús Leguina. A constituição espanhola e a fuga do direito administrativo.

Genesis: Revista de Direito Administrativo Aplicado. Curitiba, ano 2, n. 6, PL 639, set. 1995. 